\title{
Electro-discharge machining of alumina: Investigation of material removal rate and surface roughness
}

\author{
M. Y. Ali' ${ }^{1}$ M. A. Moudood ${ }^{1,2}$, M. A. Maleque ${ }^{1}$, M. Hazza and E. Y. T. Adesta ${ }^{1, *}$ \\ ${ }^{1}$ Department of Manufacturing and Materials Engineering \\ International Islamic University Malaysia, PO Box 10, \\ 50728 Kuala Lumpur, Malaysia \\ ${ }^{2}$ Griffith School of Engineering, Gold Coast Campus \\ Griffith University, Queensland 4222, Australia \\ * E-mail: eadesta@iium.edu.my
}

\begin{abstract}
Alumina is a non-conductive ceramic material which can meet the high demand of industrial applications due to its excellent physical and chemical properties. However, machining of alumina is not possible by using the conventional machining methods due to its inherent brittleness. Recently, electro-discharge machining has been used for structuring alumina with assisting electrode to initiate the spark between the conductive tool electrode and the non-conductive work piece material. However, the effects of process parameters on material removal rate and surface roughness have not been investigated to formulate mathematical models. This study dealt with developing models for material removal rate and surface roughness correlating three process parameters which are peak current, pulse-on time and gap voltage using response surface methodology. The models were verified with $7 \%$ error between the results of empirical models and the experimental values.
\end{abstract}

Keywords: Electro-discharge machining; non-conductive ceramic; assisting electrode; response surface methodology; material removal rate; surface roughness.

\section{INTRODUCTION}

Since electro-discharge machining (EDM) is a precise material removal process, it has been popularly applied for the machining of conductive materials with a minimum of 0.10 S.cm ${ }^{-1}$ electrical conductivity $[1,2]$. Electrical conductivity of selected materials is shown in Table 1 and the physical properties of $\mathrm{Al}_{2} \mathrm{O}_{3}$ are listed in Table 2. However, with the use of assisting electrode, the EDM process has already been applied in machining nonconductive ceramic materials [3-7]. In the case of carbonic dielectric fluid, the cracked polymer chains produce carbon black which combines with debris and forms a conductive layer on ceramic surface [8]. This modified process and its performance is found to be different from cutting conductive materials. Several researches were carried out to investigate the EDM process parameters for the machining of nonconductive ceramic [912]. It is shown that the maximum $M R R$ and minimum $R_{a}$ can be produced with the combined effect of low pulse time and high peak current, rotational speed, and flushing pressure. Alumina $\left(\mathrm{Al}_{2} \mathrm{O}_{3}\right)$, a non-conductive ceramic material, can be machined by EDM with the help of assisting electrode. In this case, a higher tool wear rate $(T W R)$ and lower assisting electrode wear rate $(A E W R)$ are obtained, along with higher crater volume 
and depth when higher capacitance and peak voltage are applied [4]. It is also observed that surface roughness increases with the increase of discharge current $[2,8]$. However, $\mathrm{EDM}$ of $\mathrm{Al}_{2} \mathrm{O}_{3}$ is found to be more difficult to machine because of the unsteady formation of electrically conductive layers on workpiece surface during the machining process [5, 13]. Under this circumstance, attaining the optimum machining outputs such as a higher $M R R$ and lower $S R$ is complicated [14]. Moreover, the mathematical models for MRR and SR for processing $\mathrm{Al}_{2} \mathrm{O}_{3}$ are using EDM. Therefore, this study focuses on the modelling and optimisation of material removal rate $(M R R)$ and average surface roughness $\left(R_{a}\right)$, where peak current, pulse-on time, and gap voltage are the input process parameters. A face-centred central composite design of RSM was used for the design of experiments. The significant process parameters were determined to yield high $M R R$ and low $R_{a}$ value by using ANOVA analysis. Finally, experiments were conducted to optimise the process parameters and the developed models were validated. The novelty of this research is the formulation of models for material removal rate and surface roughness for $\mathrm{Al}_{2} \mathrm{O}_{3}$ when machined with EDM. Now, MRR and surface roughness can be estimated based on the process parameters of peak current, pulse-on time, and gap voltage.

Table 1. Electrical conductivity of selected materials [7].

\begin{tabular}{cccc}
\hline Non-conductive & Partially conductive & Conductive & $\begin{array}{c}\text { Electrical } \\
\text { conductivity }\left(\mathrm{S} . c m^{-1}\right)\end{array}$ \\
\hline $\begin{array}{c}\text { Diamond } \\
\mathrm{Al}_{2} \mathrm{O}_{3}\end{array}$ & & $10^{-16}$ \\
$\mathrm{Si}_{3} \mathrm{~N}_{4}$ & & $10^{-14}$ \\
$\mathrm{ZrO}_{2}$ & & $10^{-13}$ \\
& & $10^{-10}$ \\
& $\mathrm{Si}$ & $10^{-4}$ \\
$\mathrm{SiC}$ & & $10^{-4}-10^{0}$ \\
& $\mathrm{~B} 4 \mathrm{C}$ & $10^{-1}-10^{1}$ \\
& & $10^{1}-10^{2}$ \\
& $\mathrm{SiSiC}$ & $10^{2}$ \\
& $\mathrm{SiN}_{4}-\mathrm{TiN}$ & $10^{3}$ \\
& $\mathrm{TiB}$ & $10^{3}$ \\
& $\mathrm{Al}_{2} \mathrm{O}_{3}-\mathrm{TiCN}$ & $10^{4}$ \\
& $\mathrm{ZrO}_{2}-\mathrm{TiN}$ & $10^{5}$ \\
& $\mathrm{Steel}$ & $10^{5}$ \\
& $\mathrm{Cu}$ & $10^{6}$ \\
& $\mathrm{Ag}$ & $10^{6}$ \\
& & $\mathrm{WC}^{6} \mathrm{Co}$ & \\
& &
\end{tabular}

Table 2. Physical properties of $\mathrm{Al}_{2} \mathrm{O}_{3}$ ceramic [14].

\begin{tabular}{cc}
\hline Property & Value \\
\hline Melting point $\left({ }^{\circ} \mathrm{C}\right)$ & 2050 \\
Thermal conductivity $(\mathrm{W} / \mathrm{m} \mathrm{K})$ & 22 \\
Density $(\mathrm{gm} / \mathrm{cc})$ & 3.69 \\
Electrical conductivity $\left(\mathrm{S} . \mathrm{cm}^{-1}\right)$ & $<10^{-14}$ \\
Hardness $(\mathrm{HV})$ & 1800 \\
Young's modulus $(\mathrm{GPa})$ & 386 \\
\hline
\end{tabular}




\section{METHODS AND MATERIALS}

\section{Experimental Setup}

Die sinking EDM machine (EX 22, Mitsubishi, Japan) was used to conduct the experiments. An electric balance (B204-S Mettler Toledo, Switzerland) with $0.01 \mathrm{mg}$ accuracy was used for weighing the workpiece before and after the machining. Alicona infinite focus microscope (IFM G4g System, Austria) was used for the measurements of surface roughness. Moreover, a scanning electron microscope (SEM) (JEOL JSM-5600, Japan) was used to investigate surface quality. The experimental setup for EDM of $\mathrm{Al}_{2} \mathrm{O}_{3}$ is shown in Figure 1. Alumina plate $(20 \mathrm{~mm} \times 15 \mathrm{~mm} \times 10 \mathrm{~mm})$ was used as the workpiece as shown in Figure 2(a). Adhesive copper $(\mathrm{Cu})$ foil was used as the assisting electrode (AE) to initiate sparks on the workpiece surface. An $85 \mathrm{~mm}$ long and $3 \mathrm{~mm}$ x $3 \mathrm{~mm}$ sized square piece of $\mathrm{Cu}$ was used as the tool electrode. Commercially available kerosene was used as the dielectric fluid in this study. It has relatively high dielectric strength with low viscosity. This procedure was adopted from published literature $[4,5,7]$.

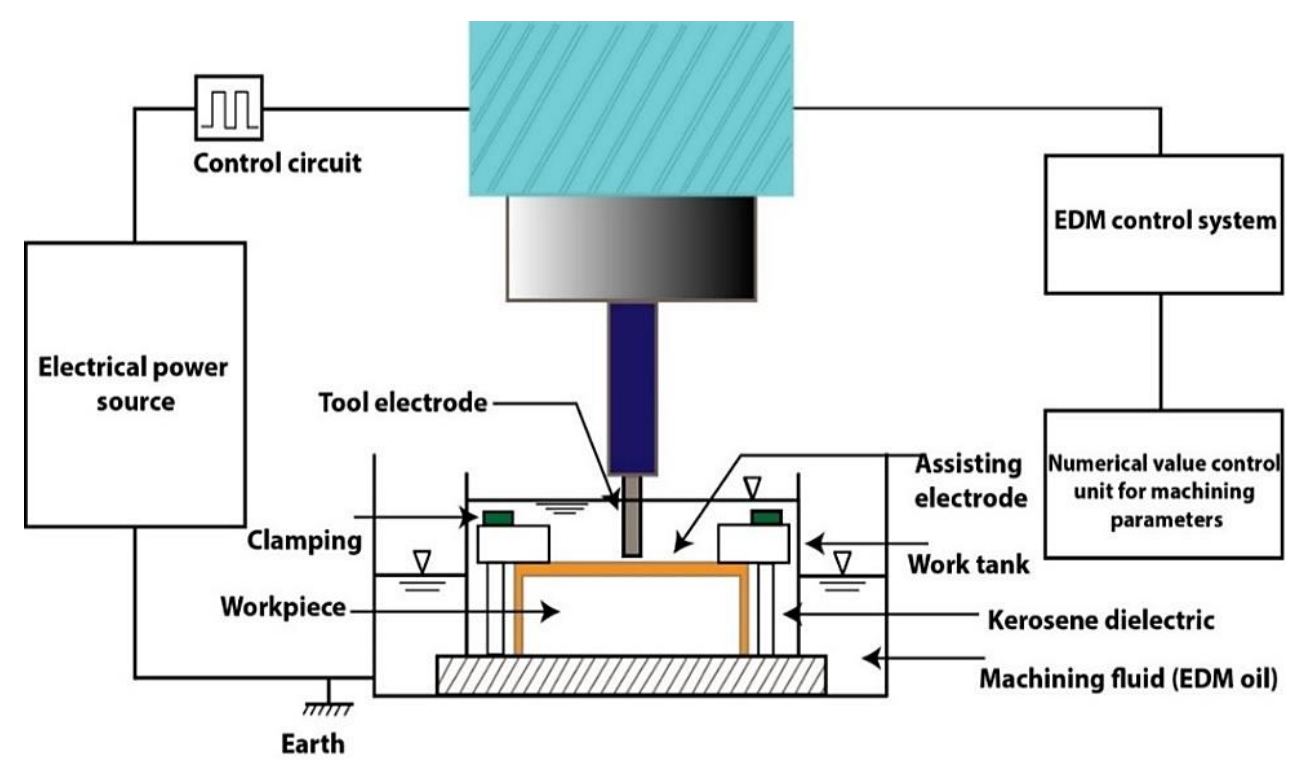

Figure 1. Schematic diagram of experimental setup for EDM of $\mathrm{Al}_{2} \mathrm{O}_{3}$.

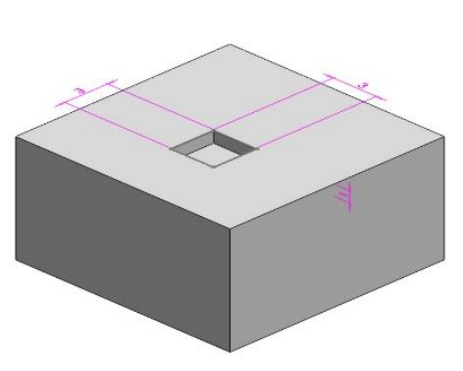

(a)

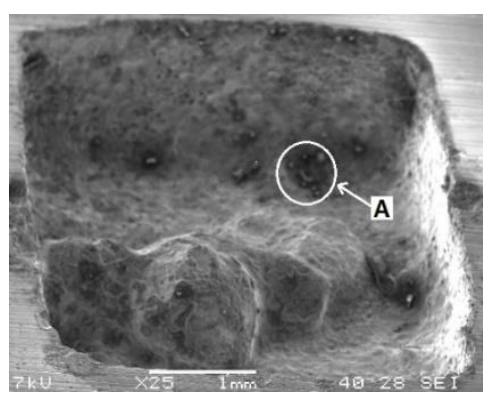

(b)

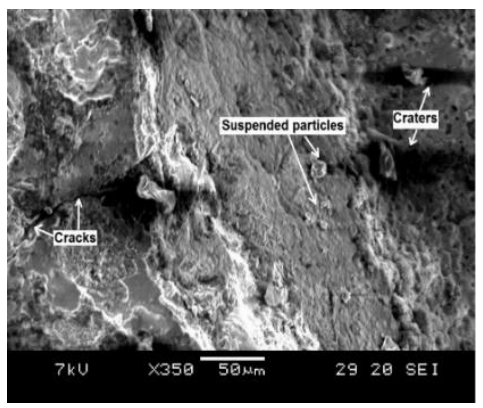

(c)

Figure 2. (a) Schematic diagram of workpiece, SEM micrograph of (b) cavity on $\mathrm{Al}_{2} \mathrm{O}_{3}$ produced by EDM and (c) enlarged view of window A to show the details of the surface texture. 
Table 3. Design outline of the independent parameters with their levels.

\begin{tabular}{ccccc}
\hline Factors & Unit & \multicolumn{3}{c}{ Levels } \\
\cline { 2 - 5 } & & -1 & 0 & +1 \\
\hline Peak current, $I_{p}$ & $\mathrm{~A}$ & 1.1 & 1.2 & 1.3 \\
Pulse-on time, $T_{o n}$ & $\mu \mathrm{s}$ & 6 & 7 & 8 \\
Gap voltage, $U$ & $\mathrm{~V}$ & 12 & 13 & 14 \\
\hline
\end{tabular}

Table 4. Experimental results of EDM characteristics in the design matrix.

\begin{tabular}{cccccc}
\hline Exp. No. & $\begin{array}{c}\text { Peak current, } \\
I_{p}(\mathrm{~A})\end{array}$ & $\begin{array}{c}\text { Pulse-on time, } \\
T_{\text {on }}(\mu \mathrm{s})\end{array}$ & $\begin{array}{c}\text { Gap voltage, } \\
U(\mathrm{~V})\end{array}$ & $\begin{array}{c}M R R \\
\left(\mathrm{~mm}^{3} / \mathrm{min}\right)\end{array}$ & $\begin{array}{c}R_{a} \\
(\mu \mathrm{m})\end{array}$ \\
\hline 1 & 1.2 & 7 & 13 & 0.0431 & 3.9804 \\
2 & 1.2 & 7 & 13 & 0.0503 & 3.9953 \\
3 & 1.2 & 7 & 13 & 0.0408 & 4.1301 \\
4 & 1.2 & 7 & 13 & 0.0419 & 4.2004 \\
5 & 1.2 & 7 & 13 & 0.0415 & 4.1825 \\
6 & 1.2 & 7 & 13 & 0.0516 & 4.4304 \\
7 & 1.2 & 6 & 13 & 0.0509 & 2.6692 \\
8 & 1.2 & 8 & 13 & 0.0526 & 4.8184 \\
9 & 1.3 & 7 & 13 & 0.0577 & 4.7436 \\
10 & 1.2 & 7 & 12 & 0.0502 & 3.1708 \\
11 & 1.2 & 7 & 14 & 0.0861 & 4.6138 \\
12 & 1.1 & 7 & 13 & 0.0409 & 3.1424 \\
13 & 1.1 & 6 & 12 & 0.0563 & 2.4717 \\
14 & 1.3 & 8 & 12 & 0.0495 & 5.1032 \\
15 & 1.3 & 8 & 14 & 0.1532 & 6.8741 \\
16 & 1.1 & 8 & 14 & 0.1295 & 4.7724 \\
17 & 1.3 & 6 & 14 & 0.0898 & 3.8231 \\
18 & 1.1 & 6 & 14 & 0.0824 & 2.5267 \\
19 & 1.1 & 8 & 12 & 0.0413 & 3.7515 \\
20 & 1.3 & 6 & 12 & 0.0676 & 2.6947 \\
\hline
\end{tabular}

\section{Parameter Selection and Design}

In the preliminary experiments, peak current $\left(I_{p}\right)$, pulse-on time $\left(T_{o n}\right)$, and gap voltage $(U)$ were found to be the most influential parameters for EDM of alumina. Continuous and steady machining occurred with these three process parameters during the initial experiments, apart from the other process parameters. The upper and lower limits of these process parameters were obtained from the preliminary experiments with one factor at a time (OFAT) approach. Further experiments were conducted to measure the EDM output parameters according to the face-centred central composite design (FCD). The number of factorial runs was obtained by $2^{\mathrm{k}}$ (here $\left.2^{3}=8\right)$, while the star points determined by $2 \mathrm{k}(2$ $x 3$ ) were equivalent to six, and six central points were included for the lack of fit test. So, the design consisted a total number of 20 experiments ( 8 factorial runs, 6 star (or axial) points, and 6 central runs). These three factors with their levels and responses were put into the central composite design of the Design-Expert 6.0.8 software to produce an overall design matrix of this study. Table 3 shows the design scheme of machining 
parameters and their levels. Out of 20 experiments, six experiments at the same combination were applied to reduce the curvature effect. Details of all 20 experiments and their measured $M R R$ and $S R$ values are listed in Table 4.

\section{RESULTS AND DISCUSSION}

The effects of the EDM process parameters $\left(I_{p}, T_{o n}, U\right)$ over the outputs, material removal rate $(M R R)$, and surface roughness $\left(R_{a}\right)$ were analysed. Experimental output values of $M R R$, and $R_{a}$, as listed in Table 4 were analysed to develop the regression equations.

\section{Mathematical Formulation of EDM Response}

The experimental data were analysed by ANOVA, as shown in Table 5, where all three models were developed with $95 \%$ confidence level, i.e. the process parameters with $\mathrm{P}$ value $<0.05$ were considered as significant terms. The insignificant terms of the response were eliminated by using the backward elimination method of RSM. The suggested quadratic model for MRR was evaluated by the F-test of ANOVA which indicated that peak current $\left(I_{p}\right)$, pulse-on time $\left(T_{o n}\right)$, gap voltage $(U)$, quadratic terms of pulse-on time and gap voltage $\left(T_{o n}^{2}, U^{2}\right)$, and the interaction term of pulse-on time and gap voltage $\left(T_{o n} U\right)$ were significant model terms. The F-value of the model was 55.68 and P-value < 0.05 indicated that the model was significant. The "Lack of fit F-value" was equal to 3.03, indicating that lack of fit was not important relative to the pure error. There was an $11.85 \%$ probability that a non-significant "Lack of fit F-value" of this order could occur due to noise. Lack of fit is good when it is non-significant. The value of predicted Rsquared was 0.8908 which was also in a logical conformity with the "adjusted R-squared" value of 0.9453 . Adequate precision measures the signal to noise ratio and its value of more than 4 is desired. In this case, this ratio obtained was 24.62, which means an adequate signal. So, the model can be used to navigate the design space. A second order quadratic model, as expressed by Eq. (1) for $M R R$ was found to be of good fit to the data.

$$
M R R=6.28+0.067 I_{p}-0.375 T_{o n}-0.8 U+0.011 T_{o n}^{2}+0.0271 U^{2}+0.018 T_{o n} U
$$

Similarly, ANOVA was performed to analyse the surface roughness. Two-factor interaction (2FI) model was suggested for the $R_{a}$ model. The P-values (Prob $>\mathrm{F}$ ) of the model with peak current $\left(I_{p}\right)$, pulse-on time $\left(T_{o n}\right)$, gap voltage $(U)$ and the interaction term $\left(I_{p} T_{o n}, I_{p} U, T_{o n} U\right)$ were found to be significant. So, these terms had a significant effect on the model. The Model F-value of 77.21 implied that the model was significant. There was only a $0.01 \%$ chance that "Model F-value" of this much magnitude could occur due to noise. Values of "Prob > F" less than 0.05 indicated that the model terms were significant. The "Lack of fit F-value" of 2.08 implied that the Lack of fit was not significant relative to the pure error. There was a $21.79 \%$ chance that a "Lack of fit F-value" of this order could occur due to noise. Non-significant lack of fit is needed for the model to fit. The "predicted R-squared" of 0.9434 was in reasonable agreement with the "adjusted Rsquared" value of 0.9601. "Adequate precision" measures the signal to noise ratio. In this study, the ratio of 36.84 indicated an adequate signal. After analysing with ANOVA, the 2FI model for $R_{a}$ was expressed in Eq. (2).

$$
R_{a}=55.44-39.98 I_{p}-4.4 T_{o n}-3.6 U+2.42 I_{p} T_{o n}+2.28 I_{p} U+0.2 T_{o n} U
$$


Table 5. ANOVA test results for the fitted models.

\begin{tabular}{|c|c|c|c|c|c|c|}
\hline Source & $\begin{array}{l}\text { Sum of } \\
\text { Squares }\end{array}$ & DF & Mean Square & $\begin{array}{c}\mathrm{F} \\
\text { Valu } \\
\mathrm{e} \\
\end{array}$ & Prob $>F$ & \\
\hline \multicolumn{7}{|c|}{ Material Removal Rate (MRR) } \\
\hline Model & 0.0167 & 6 & 0.002874 & 55.68 & $<0.0001$ & Significant \\
\hline Residual & 0.000671 & 13 & 0.00005162 & & & \\
\hline $\begin{array}{l}\text { Lack of } \\
\text { Fit }\end{array}$ & 0.0005564 & 8 & 0.00006954 & 3.03 & 0.1185 & $\begin{array}{c}\text { Not } \\
\text { significant }\end{array}$ \\
\hline Pure Error & 0.0001147 & 5 & 0.00002293 & & & \\
\hline Cor. Total & 0.018 & 19 & & & & \\
\hline \multicolumn{4}{|c|}{$\begin{array}{r}\text { Coefficient of variation }=11.25 \\
\text { Predicted residual error of sum of square }(\text { PRESS) } \\
=0.001957\end{array}$} & & \multicolumn{2}{|c|}{$\begin{aligned} \mathrm{R}^{2} & =0.9625 \\
\text { Adjusted } \mathrm{R}^{2} & =0.9453 \\
\text { Predicted } \mathrm{R}^{2} & =0.8908 \\
\text { Adequate precision } & =24.627\end{aligned}$} \\
\hline \multicolumn{7}{|c|}{ Average Surface Roughness $\left(R_{a}\right)$} \\
\hline Model & 20.86 & 6 & 3.48 & $\begin{array}{c}77.2 \\
1\end{array}$ & $<0.0001$ & Significant \\
\hline Residual & 0.59 & 13 & 0.045 & & & \\
\hline Lack of Fit & 0.45 & 8 & 0.056 & 2.08 & 0.2179 & $\begin{array}{c}\text { Not } \\
\text { significant }\end{array}$ \\
\hline $\begin{array}{l}\text { Pure Error } \\
\text { Cor. Total }\end{array}$ & $\begin{array}{c}0.14 \\
21.45\end{array}$ & $\begin{array}{c}5 \\
19\end{array}$ & 0.027 & & & \\
\hline Predictec & residual err & $\begin{array}{r}\text { Sta } \\
\text { oeffi } \\
\text { of sur }\end{array}$ & $\begin{array}{r}\text { deviation }=0 \\
\text { Mean }=4 \\
\text { of variation }= \\
\text { square }(\text { PRESS } \\
1 .\end{array}$ & & $\begin{array}{r}\text { Adjus } \\
\text { Predict } \\
\text { Adequate pr }\end{array}$ & $\begin{array}{r}R^{2}=0.9727 \\
\mathrm{~d} \mathrm{R}^{2}=0.9601 \\
\mathrm{~d}^{2}=0.9434 \\
\text { ision }=36.84\end{array}$ \\
\hline
\end{tabular}

\section{Effect of Process Parameters on EDM Response}

The SEM micrograph of the EDMed cavity, as shown in Figures 2(b-c), yielded an idea about the machined surface texture. It revealed a lot of cracks, micro-cracks, craters and solidified debris particles that existed on the machined surface. These were responsible for the higher surface roughness and low $M R R$. Presence of cracks, micro-cracks, and so on demonstrated that spalling occurred, which was a common phenomenon for all nonconductive materials when machined with EDM.

\section{Effect on Material Removal Rate}

The estimated 2D contour plot for $M R R$ with respect to the design parameters of gap voltage and pulse-on time when peak current was placed on the central value is shown in Figure 3. It can be seen that the highest $M R R$ occurred at the maximum gap voltage and pulse-on time level. Gap voltage has significant effect on $M R R$. MRR increases nonlinearly with gap voltages for any value of the pulse-on time. Pulse-on time has a trivial effect on $M R R$ as compared to gap voltage. Similar results were found in the previous studies $[15,16]$. Gap voltage is essentially correlated to spark gap and dielectric strength. When a higher voltage is set, a higher spark gap is produced. As a result of higher spark gap, flushing conditions were improved in achieving higher $M R R$ and a rough surface was produced. Additionally, electric field strength increased with the increase of open 
circuit voltage which resulted in higher $M R R$. Based on the investigation, the rate of material removal for alumina was significantly different from other non-conductive ceramics.

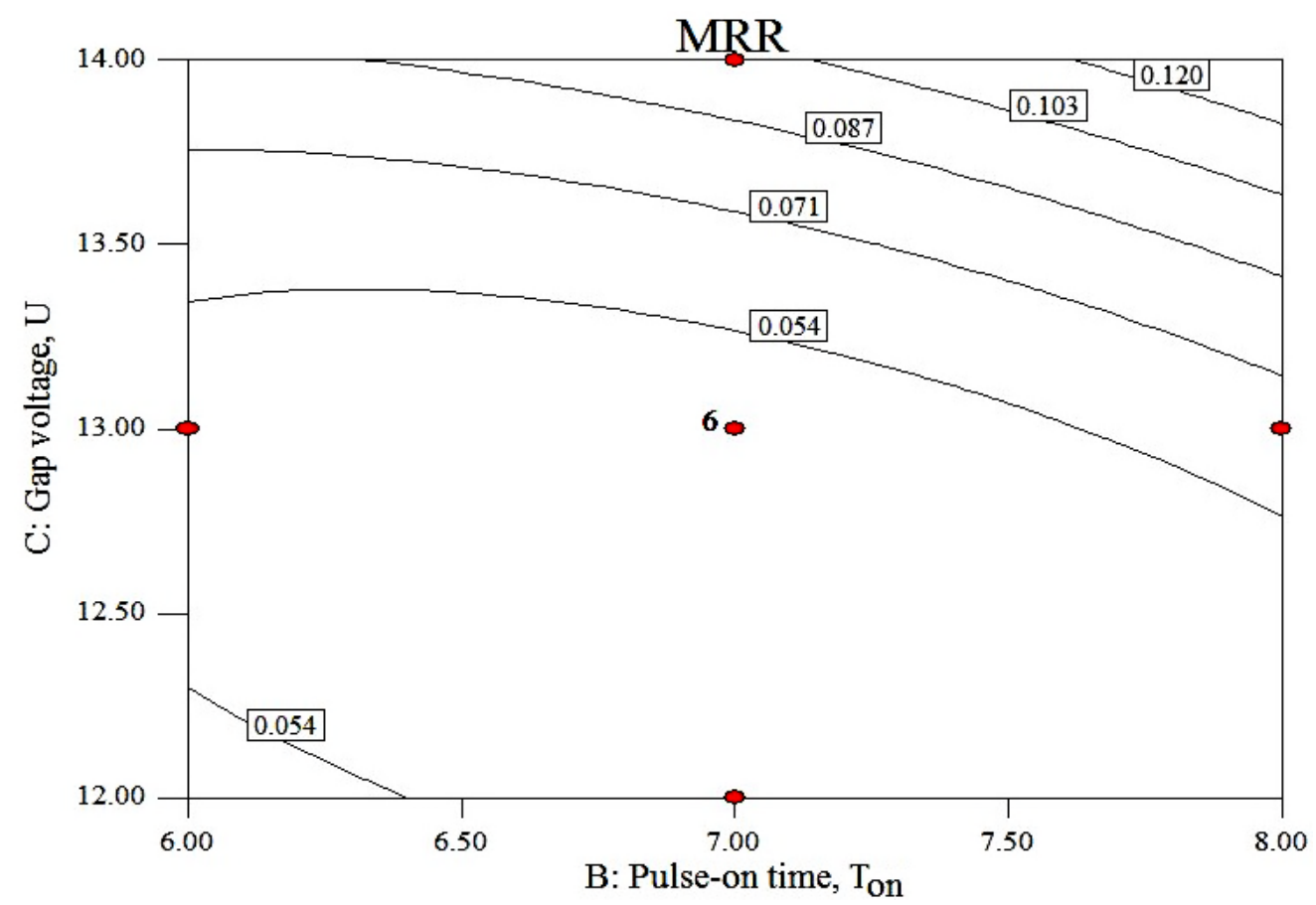

Figure 3. Combined effect of gap voltage and pulse-on time on $M R R$ when $I_{p}=1.2 \mathrm{~A}$.

\section{Effect on Average Surface Roughness}

The effect of process parameters on $R_{a}$ was investigated by using the contour plots (Figure 4). It was well defined from the contour plots that increasing pulse-on time, peak current, and gap voltage also increased the surface roughness. The pulse-on time had a significantly high effect on the responses (Figure 4(a) and Figure 4(c)). Slight increase in pulse-on time resulted in higher increase in surface roughness. Peak current also caused a significant effect on the response surface. Gap voltage had a minor effect on the responses. Figure 4(a) shows the combined effect of peak current and pulse-on time on $R_{a} . R_{a}$ was found to be the maximum at the highest level of peak current and pulse-on time. $R_{a}$ increased with the increase of pulse-on time at different peak currents. Significantly, smooth surfaces were found at the lower range of pulse-on time and peak current. Among the two parameters, pulse-on time had more influence on $R_{a}$. Surface roughness is very much related to the spark energy and spark energy is a function of current, pulse-on time, etc. So, when $I_{p}, T_{o n}$ increased, then spark energy also increased which resulted in a higher $R_{a}$. Figure 4(b) presents the combined effect of gap voltage and peak current on $R_{a}$. Surface roughness of the machined surface increased with the increase of both gap voltage and peak current. Similar investigation was observed in the EDM of $\mathrm{Al} / \mathrm{SiC}$ metal matrix composite workpiece when $\mathrm{Cu}$ was used as a tool electrode. It was thought that the growth in peak current caused an increment in the discharge heat energy at the point where the discharge occurred. At that point, overheated molten materials were created and evaporated to form gas bubbles. These gas bubbles carried the melted materials away during that discharge. 

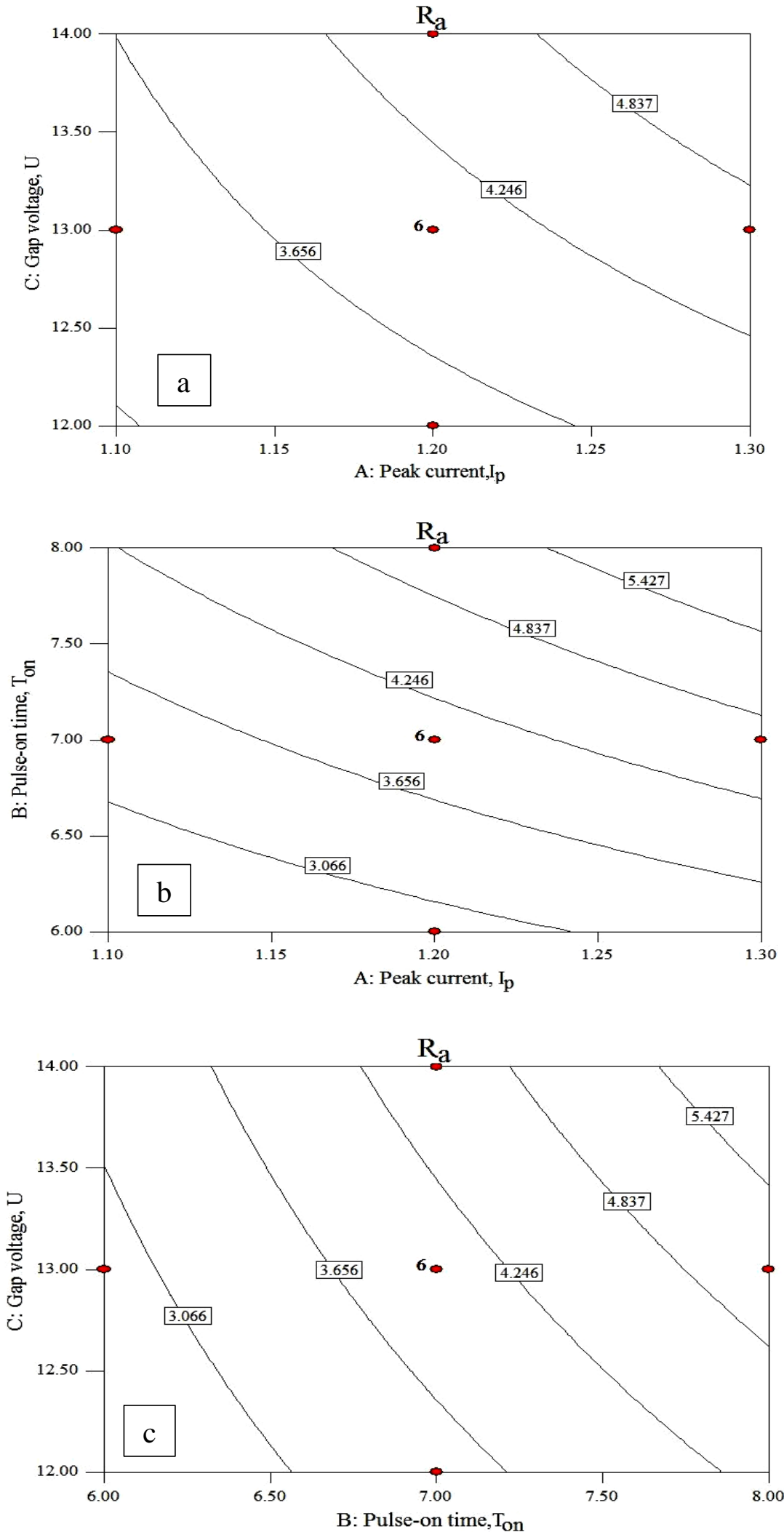

Figure 4. Combined effect of (a) peak current and pulse-on time on $R_{a}$ when $U$ $=13 \mathrm{~V}$, (b) gap voltage and peak current on $R_{a}$ when $T_{o n}=7 \mu \mathrm{s}$, and (c) gap voltage and pulse-on time on $R_{a}$ when $I_{p}=1.2 \mathrm{~A}$. 
The ensuing discharges will result in craters and pock marks, accordingly increasing the surface roughness $[17,18]$. Figure 4(c) presents the combined effect of gap voltage and pulse-on time on $R_{a} . R_{a}$ increased linearly with the increase of both pulse-on time and gap voltage. However, an increase in pulse-on time increased the surface roughness significantly, whereas gap voltage increment had less effect on the surface roughness. This was justified by the previous studies [17-20]. Furthermore, higher pulseon time increased the plasma channel diameter which minimised both energy density and impulsive force. The reduction in impulsive force resulted in poor flushing of the melted debris which eventually formed a recast layer on the EDMed surface [2, 21]. However, low pulse-on time with moderate peak current produced a plasma channel with higher energy density which can create a less rough surface $[19,20]$.

\section{Multiple Response Optimisation based on Desirability}

The desirable process condition may be different for the different responses, so all the goals needed to be combined into one objective function for making optimisation easy. That way, multiple responses optimisation can be done by using the desirability function. The desired goals of the responses were set as target, maximising or minimising within the ranges of the input factors during optimisation [22]. The desired input factors peak current, pulse-on time, gap voltage were found for the output responses $M R R$, and $R_{a}$, in this technique. The optimisation concern was to have a set of machining conditions that will maximise the $M R R$ at the minimum possible $R_{a}$. The selected numerical optimisation solutions for the machining conditions were obtained. It was seen that high gap voltage $(14 \mathrm{~V})$ and low value of peak current $(1.1 \mathrm{~A})$ and pulse-on time $(6 \mu \mathrm{s})$ produced high $M R R$ and low $R_{a}$, with a desirability of 0.670 . According to this solution, the maximum MRR of $0.078 \mathrm{~mm}^{3} / \mathrm{min}$ and minimum $R_{a}$ of $2.589 \mu \mathrm{m}$ can be possible with a $67 \%$ desirability.

\section{Confirmation Experiments}

Experiments were conducted to validate the machining conditions as found during the optimisation process. The predicted responses were estimated by using the optimal values of the input factors as found from optimisation, but the actual response values were obtained from the experiments. In order to estimate the accuracy, experiments were done by taking the optimised values. The actual values were compared with the predicted values and percentage errors were calculated by using actual values as reference. The results of the confirmation experiments for $M R R$, and $R_{a}$, are shown in Table 6 . The percentage errors 5-11\%, and 3-10\% were observed for MRR and $R_{a}$ respectively. Figure 5 shows the comparison between the predicted and actual responses. Several researchers have used experimental approach design and semi-empirical models for $M R R, T W R$, and surface roughness were established with some process parameters. It was found that the average errors between the experimental and predicted values for $M R R$ and surface roughness were within $10-20 \%$ [23, 24]. Thus, the validity of optimisation for multiresponses was confirmed. So, errors found in the study were in the considering ranges and $M R R$, and $R_{a}$ can be calculated using the established models for the three process parameters $I_{p}, T_{o n}$ and $U$. 
Table 6. Results of the confirmation experiments for $M R R$, and $R_{a}$ for optimum machining parameters of $14 \mathrm{~V}$ gap voltage, 1.1 A peak current and $6 \mu$ s pulse-on time.

\begin{tabular}{cccccc}
\hline \multicolumn{3}{c}{$M R R\left(\mathrm{~mm}^{3} / \mathrm{min}\right)$} & \multicolumn{3}{c}{$R_{a}(\mu \mathrm{m})$} \\
Predicted & Actual & \% error & Predicted & Actual & \% error \\
\hline 0.078 & 0.083 & 6.4 & 2.59 & 2.51 & 3.1 \\
& 0.082 & 5.1 & & 2.85 & 10.0 \\
& 0.087 & 11.5 & & 2.49 & 3.8 \\
\hline
\end{tabular}

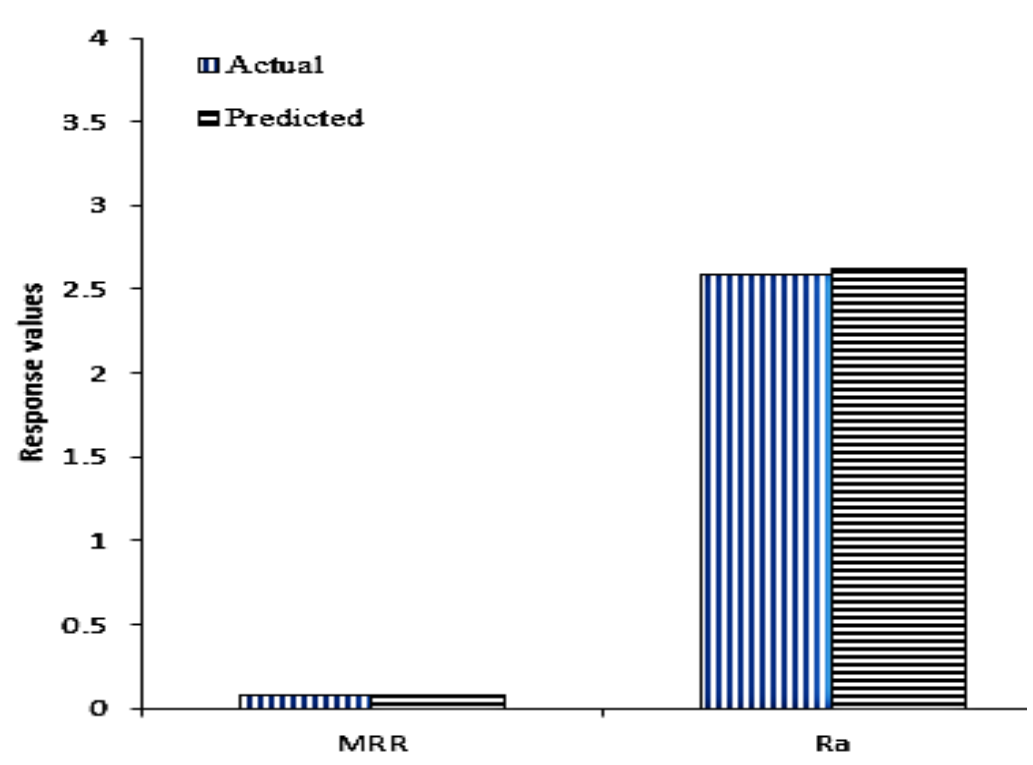

Figure 5. Comparison of predicted vs. actual responses for $M R R\left(\mathrm{~mm}^{3} / \mathrm{hr}\right)$ and $R_{a}(\mu \mathrm{m})$.

\section{CONCLUSIONS}

The die sinking EDM on alumina workpiece has been done successfully in this study. The input variables (peak current, pulse-on time and gap voltage) were used to obtain an empirical relationship with the EDM output characteristics $\left(M R R\right.$, and $\left.R_{a}\right)$. RSM was used to design and analyse the experiments and empirical models were formulated for industrial application to machine alumina with EDM. The experimental results have the conformity with the developed models. The specific conclusions are as follows:

a) This study indicates that the process parameters affected the $M R R$ and $S R\left(R_{a}\right)$ during EDM of alumina. In the case of $M R R$, gap voltage was found to be the dominant factor. However, peak current and pulse-on time were the dominant factors for $R_{a}$.

b) The ANOVA analysis showed that the developed models can predict the $M R R$ and $S R$ within $95 \%$ of confidence level. Another important measure for the regression models during ANOVA analysis was the coefficient of determination $\left(R^{2}\right)$. The $R^{2}$ values were found to be $96 \%$ for $M R R, 97 \%$ for $R_{a}$. So, it was revealed that the predicted values matched with the experimental results fairly well.

c) The optimum parameters were found by multiple response optimisations. The optimised input parameters at which maximum $M R R$ and minimum $R_{a}$ can be achieved were at $1.1 \mathrm{~A}$ peak current, $6 \mu$ s pulse-on time and $14 \mathrm{~V}$ gap voltage. 
These optimised values of $M R R$, and $R_{a}$ were $0.078 \mathrm{~mm}^{3} / \mathrm{hr}$ and $2.589 \mu \mathrm{m}$ respectively.

d) Experiments were conducted with the optimised EDM parameters found in the multiple response optimisation to check the validity of the models. The average percentage error for $M R R$, and $R_{\mathrm{a}}$ was found to be within $7 \%$.

e) Therefore, this study can be a reference for the EDM users for alumina workpiece in industrial applications for manufacturing cost and time.

f) More comprehensive experimental investigations can be extended with a bigger window of parameters.

\section{ACKNOWLEDGEMENTS}

The authors would like to express their thanks to the Ministry of Science, Technology, and Innovation (MOSTI), Malaysia for providing the financial support for this study under the Research Project 03-01-08-SF0135.

\section{REFERENCES}

[1] Schubert A, Zeidler H, Kühn R, Hackert-Oschätzchen M. Microelectrical discharge machining: A suitable process for machining ceramics. Journal of Ceramics. 2015;2015:1-9.

[2] Banu A, Abu Bakar M, Ali MY, Adesta EYT. Analysis of WEDM Process parameters on surface roughness and kerf using Taguchi method. International Journal of Engineering Materials and Manufacture. 2017;2.

[3] Patel KM, Pandey PM, Rao PV. Determination of an optimum parametric combination using a surface roughness prediction model for EDM of $\mathrm{Al}_{2} \mathrm{O}_{3} / \mathrm{SiCw} / \mathrm{TiC}$ ceramic composite. Materials and Manufacturing Processes. 2009;24:675-82.

[4] Liu YH, Ji RJ, Li XP, Yu LL, Zhang HF. Electric discharge milling of insulating ceramics. Proceedings of the Institution of Mechanical Engineers, Part B: Journal of Engineering Manufacture. 2008;222:361-6.

[5] Ji R, Liu Y, Zhang Y, Wang F, Cai B, Fu X. Single discharge machining insulating $\mathrm{Al}_{2} \mathrm{O}_{3}$ ceramic with high instantaneous pulse energy in kerosene. Materials and Manufacturing Processes. 2012;27:676-82.

[6] Muttamara A, Fukuzawa Y, Mohri N, Tani T. Effect of electrode material on electrical discharge machining of alumina. Journal of Materials Processing Technology. 2009;209:2545-52.

[7] Banu A, Ali MY, Rahman MA. Micro-electro discharge machining of nonconductive zirconia ceramic: investigation of MRR and recast layer hardness. The International Journal of Advanced Manufacturing Technology. 2014;75:257-67.

[8] Mohri N, Fukuzawa Y, Tani T, Sata T. Some Considerations to Machining Characteristics of Insulating Ceramics-Towards Practical Use in Industry. CIRP Annals. 2002;51:161-4.

[9] Banu A, Ali MY. Electrical discharge machining (EDM): a review. Int $\mathbf{J}$ Engineering Materials Manufacture. 2016;1:3-10.

[10] Ndaliman MB, Khan AA, Ali MY. Influence of electrical discharge machining process parameters on surface micro-hardness of titanium alloy. Proceedings of the Institution of Mechanical Engineers, Part B: Journal of Engineering Manufacture. 2013;227:460-4. 
[11] Chiang K-T. Modeling and analysis of the effects of machining parameters on the performance characteristics in the EDM process of $\mathrm{Al}_{2} \mathrm{O}_{3}+\mathrm{TiC}$ mixed ceramic. The International Journal of Advanced Manufacturing Technology. 2007;37:52333.

[12] Liu YH, Li XP, Ji RJ, Yu LL, Zhang HF, Li QY. Effect of technological parameter on the process performance for electric discharge milling of insulating $\mathrm{Al}_{2} \mathrm{O}_{3}$ ceramic. Journal of Materials Processing Technology. 2008;208:245-50.

[13] Fukuzawa Y, Mohri N, Tani T, Muttamara A. Electrical discharge machining properties of noble crystals. Journal of Materials Processing Technology. 2004;149:393-7.

[14] Kucukturk G, Cogun C. A new method for machining of electrically nonconductive workpieces using electric discharge machining technique. Machining Science and Technology. 2010;14:189-207.

[15] Kansal H, Singh S, Kumar P. Application of Taguchi method for optimisation of powder mixed electrical discharge machining. International Journal of Manufacturing Technology and Management. 2005;7:329-41.

[16] Kansal HK, Singh S, Kumar P. Parametric optimization of powder mixed electrical discharge machining by response surface methodology. Journal of Materials Processing Technology. 2005;169:427-36.

[17] Habib SS. Study of the parameters in electrical discharge machining through response surface methodology approach. Applied Mathematical Modelling. 2009;33:4397-407.

[18] Müller F, Monaghan J. Non-conventional machining of particle reinforced metal matrix composite. International Journal of Machine Tools and Manufacture. 2000;40:1351-66.

[19] Banerjee S, Mahapatro D, Dubey S. Some study on electrical discharge machining of $(\{\mathrm{WC}+\mathrm{TiC}+\mathrm{TaC} / \mathrm{NbC}\}-\mathrm{Co})$ cemented carbide. The International Journal of Advanced Manufacturing Technology. 2008;43:1177-88.

[20] Assarzadeh S, Ghoreishi M. A dual response surface-desirability approach to process modeling and optimization of $\mathrm{Al}_{2} \mathrm{O}_{3}$ powder-mixed electrical discharge machining (PMEDM) parameters. The International Journal of Advanced Manufacturing Technology. 2012;64:1459-77.

[21] Singh J, Singh S, Singh G. Study of surface roughness for discontinuous ultrasonic vibration assisted electric discharge machining using RSM. International Journal of Engineering Research and Technology. 2013;2:727-37.

[22] Whitcomb PJ, Anderson MJ. RSM simplified: optimizing processes using response surface methods for design of experiments: CRC press; 2004.

[23] Tsai K-M, Wang P-J. Semi-empirical model of surface finish on electrical discharge machining. International Journal of Machine Tools and Manufacture. 2001;41:1455-77.

[24] Wang P-J, Tsai K-M. Semi-empirical model on work removal and tool wear in electrical discharge machining. Journal of Materials Processing Technology. 2001;114:1-17. 